OPEN ACCESS

Edited by:

Umut Kirli,

Ege University, Turkey

Reviewed by:

Michihisa Umetani,

University of Houston, United States

Gérard Lizard,

Université de Bourgogne, France

*Correspondence:

Chuanyue Wang

wcyadyy@163.com

Rena Li

renali@ccmu.edu.cn

Specialty section:

This article was submitted to

Schizophrenia,

a section of the journal

Frontiers in Psychiatry

Received: 19 May 2021

Accepted: 05 July 2021

Published: 02 August 2021

Citation:

Sun Z, Zhao L, Bo Q, Mao Z, He Y, Jiang T, Li Y, Wang C and LiR (2021) Brain-Specific Oxysterols and Risk of Schizophrenia in Clinical High-Risk

Subjects and Patients With

Schizophrenia.

Front. Psychiatry 12:711734.

doi: 10.3389/fpsyt.2021.711734

\section{Brain-Specific Oxysterols and Risk of Schizophrenia in Clinical High-Risk Subjects and Patients With Schizophrenia}

\author{
Zuoli Sun ${ }^{1}$, Lei Zhao ${ }^{1}$, Qijing Bo ${ }^{1}$, Zhen Mao ${ }^{1}$, Yi He ${ }^{1}$, Tao Jiang ${ }^{1}$, Yuhong $\mathrm{Li}^{1,2}$, \\ Chuanyue Wang ${ }^{1,3 *}$ and Rena $L^{1,2 *}$
}

${ }^{1}$ The National Clinical Research Center for Mental Disorders and Beijing Key Laboratory of Mental Disorders, Beijing Anding Hospital, Capital Medical University, Beijing, China, ${ }^{2}$ Beijing Institute for Brain Disorders, Capital Medical University, Beijing, China, ${ }^{3}$ Advanced Innovation Center for Human Brain Protection, Capital Medical University, Beijing, China

Accumulating evidence from clinical, genetic, and epidemiologic studies suggest that schizophrenia might be a neuronal development disorder. While oxysterols are important factors in neurodevelopment, it is unknown whether oxysterols might be involved in development of schizophrenia. The present study investigated the relationship between tissue-specifically originated oxysterols and risk of schizophrenia. A total of 216 individuals were recruited in this study, including 76 schizophrenia patients, 39 clinical high-risk (CHR) subjects, and 101 healthy controls $(\mathrm{HC})$. We investigated the circulating levels of brain-specific oxysterol 24(S)-hydroxycholesterol $(24 \mathrm{OHC})$ and peripheral oxysterol 27-hydroxycholesterol $(27 \mathrm{OHC})$ in all participants and analyzed the potential links between the oxysterols and specific clinical symptoms in schizophrenic patients and $\mathrm{CHR}$. Our data showed an elevation of $24 \mathrm{OHC}$ in both schizophrenia patients and $\mathrm{CHR}$ than that in $\mathrm{HC}$, while a lower level of $27 \mathrm{OHC}$ in the schizophrenia group only. The ratio of $24 \mathrm{OHC}$ to $27 \mathrm{OHC}$ was only increased in the schizophrenic group compared with $\mathrm{CHR}$ and $\mathrm{HC}$. For the schizophrenic patients, the circulating $24 \mathrm{OHC}$ levels are significantly associated with disease duration, positively correlated with the positive and negative syndrome total scores, while the $27 \mathrm{OHC}$ levels were inversely correlated with the positive symptom scores. Together, our data demonstrated the disruption of tissue-specifically originated cholesterol metabolism in schizophrenia and $\mathrm{CHR}$, suggesting the circulating $24 \mathrm{OHC}$ or $24 \mathrm{OHC} / 27 \mathrm{OHC}$ ratio might not only be a potential indicator for risk for schizophrenia but also be biomarkers for functional abnormalities in neuropathology of schizophrenia.

Keywords: schizophrenia, cholesterol metabolism, biomarker, 24(S)- hydroxycholesterol, 27-hydroxycholesterol

\section{INTRODUCTION}

Schizophrenia is a chronic mental disorder characterized by delusions, hallucinations, impaired cognition, behavior, or emotions. While the actual causes of schizophrenia are not fully understood, recent studies support the neurodevelopmental hypothesis of schizophrenia (1). Cholesterol is well-known for its roles in brain development, such as proper myelination, 
dendritic differentiation, and synaptic plasticity in central nervous system (CNS) (2-4). While circulating cholesterol is not able to cross the blood-brain barrier (BBB) into the brain, brain synthesize cholesterol locally for cell maintenance, neuronal transmission, and synapse formation. Studies have shown that maining cholesterol homeostasis is essential for proper cellular and systemic functions, while disturbance cholesterol homeostasis might increase risks for many neurodevelopmental disorders (5-7). Although schizophrenia is a developmental disease and alteration of circulating cholesterol levels were reported in schizophrenic patients (8-12), it is unclear whether brain and peripheral cholesterol metabolism are disturbanced in schizophrenia and what their relationship related to this disease.

Oxysterols, the oxidized forms of cholesterol are able to cross BBB from peripheral to brain and vice versa (13). 24(S)-Hydroxycholesterol (24OHC), for example, is the major cholesterol metabolite in the brain by brain-specific enzyme CYP46A1. The plasma level of $24 \mathrm{OHC}$ is considered a surrogate marker for brain cholesterol metabolism since more than $90 \%$ of plasma $24 \mathrm{OHC}$ can be attributed to the brain $(14,15)$. It has been confirmed that the level of circulating $24 \mathrm{OHC}$ derived from the brain (16) is positively correlated with the $24 \mathrm{OHC}$ level in the CSF (17). In contrast to the brain-specifically originated $24 \mathrm{OHC}, 27$-hydroxycholesterol $(27 \mathrm{OHC})$ as the most abundant oxysterol in the circulating system is the product of 27-hydroxylase (CYP27A1), mainly formed from peripheral as extrahepatic and extracerebral cholesterol (13).

Cumulating evidence indicates the positive role of $24 \mathrm{OHC}$ on dendritic spines, synaptic plasticity, and synaptic vesicle cycling (18-20). As an allosteric modulator of the NMDA receptors, $24 \mathrm{OHC}$ also increases synaptic plasticity in hippocampal slices $(21,22)$. Due to the important role of oxysterols during neurodevelopment and cognition, many studies indicated the impact of oxysterol disturbance in brain disorders, such as Alzheimer's disease (23-25), amyotrophic lateral sclerosis (26), Parkinson's disease (27), major depressive disorder (MDD) (28), and autism spectrum disorder (ASD) (29). Although accumulating evidence indicates the lipid metabolism, such as eicosanoid signaling were associated with the pathophysiology of schizophrenia $(30,31)$, cholesterol metabolism and oxysterols in schizophrenia is not well-studied. A recent study reported no significant difference in plasma $24 \mathrm{OHC}$ levels between schizophrenic patients and healthy controls (32), and one study used 24OHC-liked compound reversed schizophrenialiked behavioral in animal models and suggested a potential therapeutic effect of $24 \mathrm{OHC}$ on schizophrenia (22). As the most abundant oxysterol in the circulating system, 27OHC levels increased when hypercholesteremia or oxidative stress $(33,34)$, and then as the mediator of the negative effects on cholesterol metabolism and cognitive function by decreasing the expression of HMG-CoA reducatase (the rate limit of cholesterol synthesis) (35). Plasma levels of $27 \mathrm{OHC}$ were proved to be associated with cognitive impairment patients, including mild cognitive impairment (MCI) and AD (36-38) due to its deleterious impact to synaptic plasticity (39-41). However, 27OHC has not been investigated previously in schizophrenia.
Given the different origins of the two oxysterols and circulating $24 \mathrm{OHC}$ and $27 \mathrm{OHC}$ could represent brain and peripheral cholesterol metabolites, we first investigated whether the two tissue-specific oxysterols were associated with risk for schizophrenia by comparing the circulating $24 \mathrm{OHC}$ and $27 \mathrm{OHC}$ levels as well as cognitive function in schizophrenic patients, CHR compared with HC. Then, we studied the impact of oxysterols in specific psychiatric symptoms in schizophrenia patients and CHR subjects. Our study suggested that tissuespecifically originated oxysterols might be valuable targets for early intervention and alternative treatment for schizophrenia.

\section{MATERIALS AND METHODS}

\section{Subjects}

This study was reviewed and ratified by the Independent Ethics Committee (IEC) of the Beijing Anding Hospital, Capital Medical University, China. Each subject provided informed written consent after the procedure had been fully explained in the present study.

Diagnosis of schizophrenia was confirmed by administering the Structured Clinical Interview for DSM-IV (SCID) by experienced psychiatrists. CHR individuals met diagnostic criteria for a psychosis-risk syndrome, the Criteria of PsychosisRisk States based on the face-to-face interview using Structured Interview for Psychosis-Risk Syndromes (SIPS) (42). Healthy controls (HCs) did not meet criteria for any prodromal syndrome, had any history of psychiatric illness or psychoactive drug use, or had no first-degree relative with mental disorders.

Participants in each group were excluded if they (1) aged under 16 or above 60; (2) had other neurological disorder; (3) had a history of drug or alcohol abuse; (4) were pregnancy or currently breastfeeding; and (5) were in significant medical conditions, including severe cardiovascular and hepatic or renal diseases.

Total of 216 participants, including 76 schizophrenia patients, 39 CHR subjects, and 101 age- and sex-matched HCs, were enrolled in this study from Beijing Anding Hospital, China (Table 1). The period from psychotic symptom appeared for the first time to the enrollment (psychotic symptom duration) was 23.79 months $(\mathrm{SD}=24.05)$ in schizophrenia patients and 25.50 months $(\mathrm{SD}=28.35)$ in CHR participants. Medication information was unavailable for six patients and five individuals in CHR group. For the patients who had medication information, 53 patients were not taking antipsychotics at the time of enrollment, while 17 patients taking antipsychotics, including risperidone, clozapine, olanzapine, quetiapine, paliperidone, and amisulpride. For the CHR subjects who had medication information, 24 subjects were not taking antipsychotics at the time of enrollment, while 10 subjects taking antipsychotics.

\section{Clinical Assessments}

Basic sociodemographic characteristics and clinical data were collected by a questionnaire specifically designed for this study. All schizophrenia patients were assessed using the Positive and Negative Syndrome Scale (PANSS) as a further assessment of the disease (43). The SIPS which includes 19 items, divided 
TABLE 1 | Demographic variables and clinical characteristics in schizophrenia patients, CHR individuals, and HCs.

\begin{tabular}{|c|c|c|c|c|c|}
\hline & HC & CHR & SCZ & $\mathbf{F}$ & $\boldsymbol{P}$ \\
\hline$N$ & 101 & 39 & 76 & & \\
\hline Age (year) & $26.45 \pm 4.57$ & $24.28 \pm 4.78$ & $25.68 \pm 6.85$ & 2.185 & 0.115 \\
\hline Gender (M/F) & $62 / 39$ & $24 / 15$ & $34 / 42$ & 5.559 & 0.062 \\
\hline Education (year) & $14.35 \pm 3.18$ & $14.39 \pm 3.02$ & $13.37 \pm 3.27$ & 2.202 & 0.113 \\
\hline BMI & $22.56 \pm 2.95$ & $23.11 \pm 2.82$ & $22.97 \pm 3.34$ & 0.369 & 0.692 \\
\hline Family history (yes/no) & 0/101 & $11 / 28$ & $15 / 57$ & 27.773 & $<0.001$ \\
\hline Illness/psychotic symptom duration (month) & - & $25.50 \pm 28.35$ & $23.79 \pm 24.05$ & 0.103 & 0.740 \\
\hline Antipsychotics (yes/no) & - & $10 / 24$ & $17 / 53$ & - & - \\
\hline Olanzepine equivalents (mg) & - & $14.00 \pm 7.75$ & $8.54 \pm 4.14$ & - & - \\
\hline \multicolumn{6}{|l|}{ Cognition } \\
\hline Information processing speed & $44.56 \pm 6.88$ & $39.03 \pm 6.78$ & $36.93 \pm 19.43$ & 4.886 & 0.015 \\
\hline Attention alertness & $45.54 \pm 9.09$ & $39.75 \pm 11.85$ & $31.43 \pm 9.17$ & 26.072 & $<0.001$ \\
\hline Working memory & $46.33 \pm 6.88$ & $35.02 \pm 17.14$ & $37.14 \pm 10.43$ & 12.435 & $<0.001$ \\
\hline Vocabulary learning & $47.51 \pm 9.44$ & $41.77 \pm 9.37$ & $38.49 \pm 9.87$ & 11.910 & $<0.001$ \\
\hline Visual learning & $46.34 \pm 10.34$ & $42.67 \pm 11.03$ & $38.38 \pm 14.48$ & 5.894 & 0.007 \\
\hline Reasoning and problem solving & $43.32 \pm 10.52$ & $39.62 \pm 10.54$ & $35.87 \pm 11.40$ & 6.768 & 0.004 \\
\hline Social cognition & $37.79 \pm 10.43$ & $37.03 \pm 8.68$ & $34.85 \pm 12.46$ & 1.475 & 0.399 \\
\hline Total MCCB scores & $44.40 \pm 5.88$ & $40.21 \pm 5.62$ & $35.88 \pm 6.36$ & 24.826 & $<0.001$ \\
\hline \multicolumn{6}{|l|}{ Psychiatric symptoms } \\
\hline SIPS & $0.76 \pm 2.69$ & $25.41 \pm 8.63$ & - & 365.055 & $<0.001$ \\
\hline PANSS positive & - & - & $23.07 \pm 5.58$ & - & - \\
\hline PANSS negative & - & - & $20.41 \pm 8.02$ & - & - \\
\hline PANSS general & - & - & $41.88 \pm 6.48$ & - & - \\
\hline PANSS total & - & - & $85.37 \pm 14.17$ & - & - \\
\hline \multicolumn{6}{|l|}{ Oxysterols } \\
\hline $24 \mathrm{OHC}(\mathrm{ng} / \mathrm{ml})$ & $24.47 \pm 8.76$ & $28.54 \pm 12.18$ & $27.89 \pm 8.95$ & 3.990 & 0.020 \\
\hline $27 \mathrm{OHC}(\mathrm{ng} / \mathrm{ml})$ & $43.14 \pm 18.30$ & $43.96 \pm 14.63$ & $32.78 \pm 11.92$ & 11.296 & $<0.001$ \\
\hline
\end{tabular}

Data was shown as mean $\pm S D$.

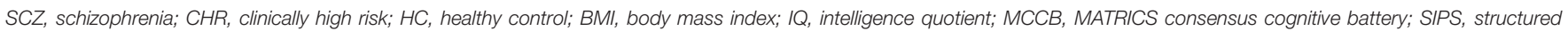

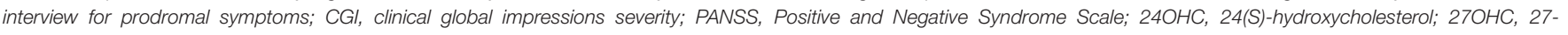
hydroxycholesterol.

into positive, negative, disorganization, and general symptom subsections, was used for identifying the state of the CHR individuals (42).

The cognitive function was assessed with MATRICS Consensus Cognitive Battery (MCCB, Chinese version) (44), which provides a comprehensive score to act as a cognitive reference point for schizophrenia individuals. In addition, the intelligence quotient (IQ) was evaluated by a Chinese version of the Wechsler Adult Intelligence Scale (45). Although all subjects completed the clinical assessments, a total of 138 subjects (50 HCs, 38 CHR individuals, and 50 schizophrenia patients) completed the cognitive evaluation.

\section{Oxysterol Analysis}

The whole blood of subjects was collected into EDTA tubes after clinical assessment at 8:00 a.m. to 15:00 p.m. Plasma was harvested after centrifugation at 3,000 rpm for $10 \mathrm{~min}$ at room temperature. Plasma levels of oxysterols were measured using high-performance liquid chromatography-mass spectrometry (HPLC-MS) as described previously with modifications (46).
Briefly, a total of $50 \mu \mathrm{l}$ plasma, $100 \mathrm{ng}$ of D5/D7 deuterium cholesterol, and $200 \mu \mathrm{l}$ acidic buffer solution (50 mM ammonium acetate, $1 \%$ formic acid, $\mathrm{pH}=3$ ) were mixed with $1 \mathrm{ml}$ methyl tert butyl ether in an eppendorf tube. Supernatant was gathered after the freezing at $-80^{\circ} \mathrm{C}$ and then dried at $30^{\circ} \mathrm{C}$. Fifty microliters of chloroform solution with $12.6 \mathrm{~g} / \mathrm{L} N, N^{\prime}$ diisopropylcarbodiimide, $12.4 \mathrm{~g} / \mathrm{L}$ nicotinamide, and $12.2 \mathrm{~g} / \mathrm{L}$ 4-dimethylaminopyridine was added to derive at $35^{\circ} \mathrm{C}$ water bath for $2 \mathrm{~h}$. The reactants were dried and dissolved in $100 \mu \mathrm{l}$ of methanol for HPLC-MS detection. HPLC with an Angilent G1312B HPLC Pump and an Angilent C18 column $(0.35 \mu \mathrm{m}$ bead size; $4.6 \times 250 \mathrm{~mm}$ ) were used for the measurement of oxysterols.

\section{Statistical Analysis}

The data was analyzed with SPSS (version 20.0, SPSS Inc., Chicago, Illinois, USA). Descriptive statistics were used to describe demographic and clinical characteristics of the participants. The variables were expressed as mean \pm standard deviation (SD). Comparisons of demographic, clinical variables, 
and oxysterol levels among groups were performed using one-way analysis of variance (ANOVA) followed by post-hoc Bonferroni multiple comparison test, while gender and family history were performed using chi-squared test. A multiple linear regression analysis was used to assess the factors affecting oxysterol levels in schizophrenia patients, including age, gender, illness duration, antipsychotics, and family history. Spearman's correlation analysis was used to evaluate the relationship between plasma oxysterol levels and clinical parameters or age in subjects. Multiple linear regression analysis was used to assess the relationship between oxysterols and demographic variables or clinical characteristics in schizophrenia patients. The receiver operating characteristic (ROC) curve and the area under the ROC curve (AUC) were used to evaluate the diagnosis value of oxysterols in schizophrenia. The level of two-tailed statistical significance was also set to $p<0.05$ for all tests.

\section{RESULTS}

Table 1 summarizes the demographic, psychiatric symptoms, and cognitive assessments of the participants.

\section{Opposite Changes Between Brain and Peripheral Cholesterol Metabolites in Participants}

Mean plasma 24OHC levels revealed a significant increase in schizophrenia patients (Table 1; Figure 1A, $p=0.045$ ) and an increase trend in CHR participants $(p=0.062)$ relative to HCs. On the other hand, schizophrenia patients showed significantly lower plasma 27OHC levels than HCs (Figure 1B, $p<0.001$ ), however, no such change was found in the CHR group.

A multiple linear regression analysis was used to assess the factors affecting oxysterol levels in schizophrenia patients, including age, gender, illness duration, antipsychotics, and family history. Significant correlations were found between $24 \mathrm{OHC}$ and age $(t=-3.141, p=0.003)$ or illness duration $(t=3.023, p=$ $0.004)$. However, sex, antipsychotics and family history had no significant influence on oxysterol levels (all $p>0.05$ ).

\section{Changes in Age-Dependent Oxysterol Levels in Schizophrenia Patients and CHR Individuals Compared With HCs}

A significant age-dependent decrease in $24 \mathrm{OHC}$ levels was found in the HCs (Figure 2A, $p=0.008$ ); however, similar correlation disappeared in $\operatorname{CHR}(p=0.880)$ or schizophrenia patients $(p=0.078)$. Interestingly, the mean 24OHC levels in different ages showed obvious change in CHR compared with $\mathrm{HCs}$, and the largest difference was found in the subjects before 25 years old among groups (Figure 2B). On the other hand, the plasma 27OHC levels showed significant age-dependent decrease in schizophrenia patients (Figure 2C, $p=0.039$ ) or unchanged in CHR individuals $(p=0.175)$, although slow age-dependent increase was found in HCs $(p=0.268)$. Unlike 24OHC, the difference in 27OHC levels among groups became more and more significant along with age (Figure 2D). Similar to $24 \mathrm{OHC}, 24 \mathrm{OHC} / 27 \mathrm{OHC}$ values were significantly age-dependent decreased in the HCs (Figure 2E, $p=0.001$ ); however, such correlation disappeared in CHR $(p=0.583)$ or schizophrenia patients $(p=0.591)$.

\section{Associations of Oxysterol Levels and Cognitive Function in Each Group}

Significant positive correlations between plasma 27OHC levels and MCCB total scores was found in HCs (Table 2, $p=0.025$ ); however, such correlation disappeared in CHR or schizophrenia patients. No significant correlation was found between plasma $24 \mathrm{OHC}$ levels and cognitive function.

\section{Associations of Oxysterol Levels and Psychiatric Symptoms in Schizophrenia Patients}

Plasma 24OHC levels increased along with the PANSS total scores in the schizophrenia patients (Table 2, $p=0.037$ ), especially negative symptom scores $(p=0.029)$. On the contrary, plasma $27 \mathrm{OHC}$ levels inversely correlated with positive symptom scores in schizophrenia patients $(p=0.010)$, although there was no significant correlation with PANSS total scores.

In order to eliminate the influence of confounding factors on psychiatric symptoms, the multiple linear regression
A

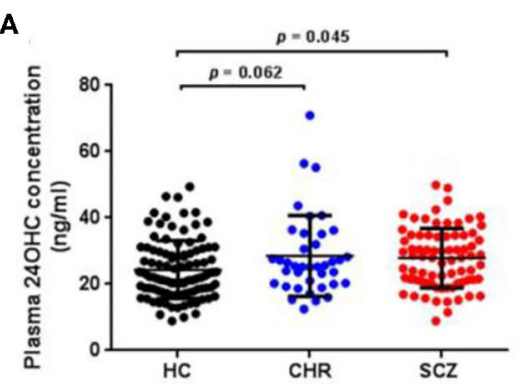

B

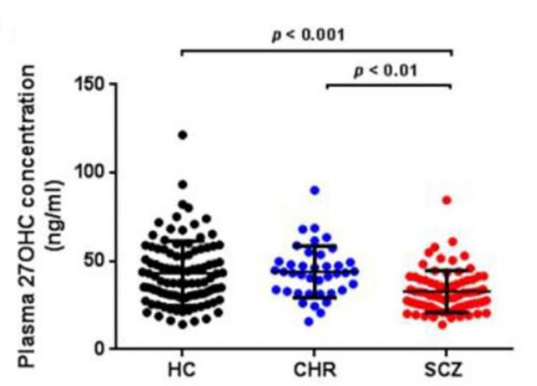

C

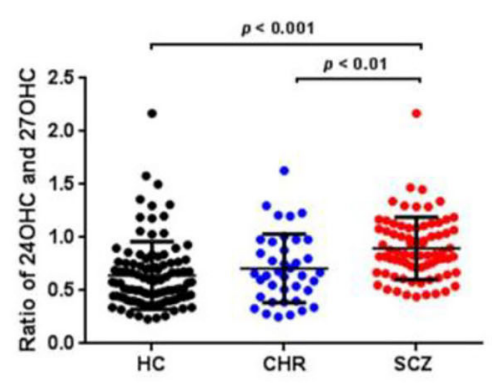

FIGURE 1 | Plasma oxysterols profile in schizophrenia (SCZ) patients, clinically high risk (CHR) individuals, and healthy controls (HC). The plasma 24OHC levels, $27 \mathrm{OHC}$ levels, and $24 \mathrm{OHC} / 27 \mathrm{OHC}$ in SCZ patients, $\mathrm{CHR}$, and $\mathrm{HC}$ are shown in (A), (B), and (C), respectively. SCZ patients showed higher plasma $24 \mathrm{OHC}$ levels and lower $27 \mathrm{OHC}$ levels than $\mathrm{HCs}$. 


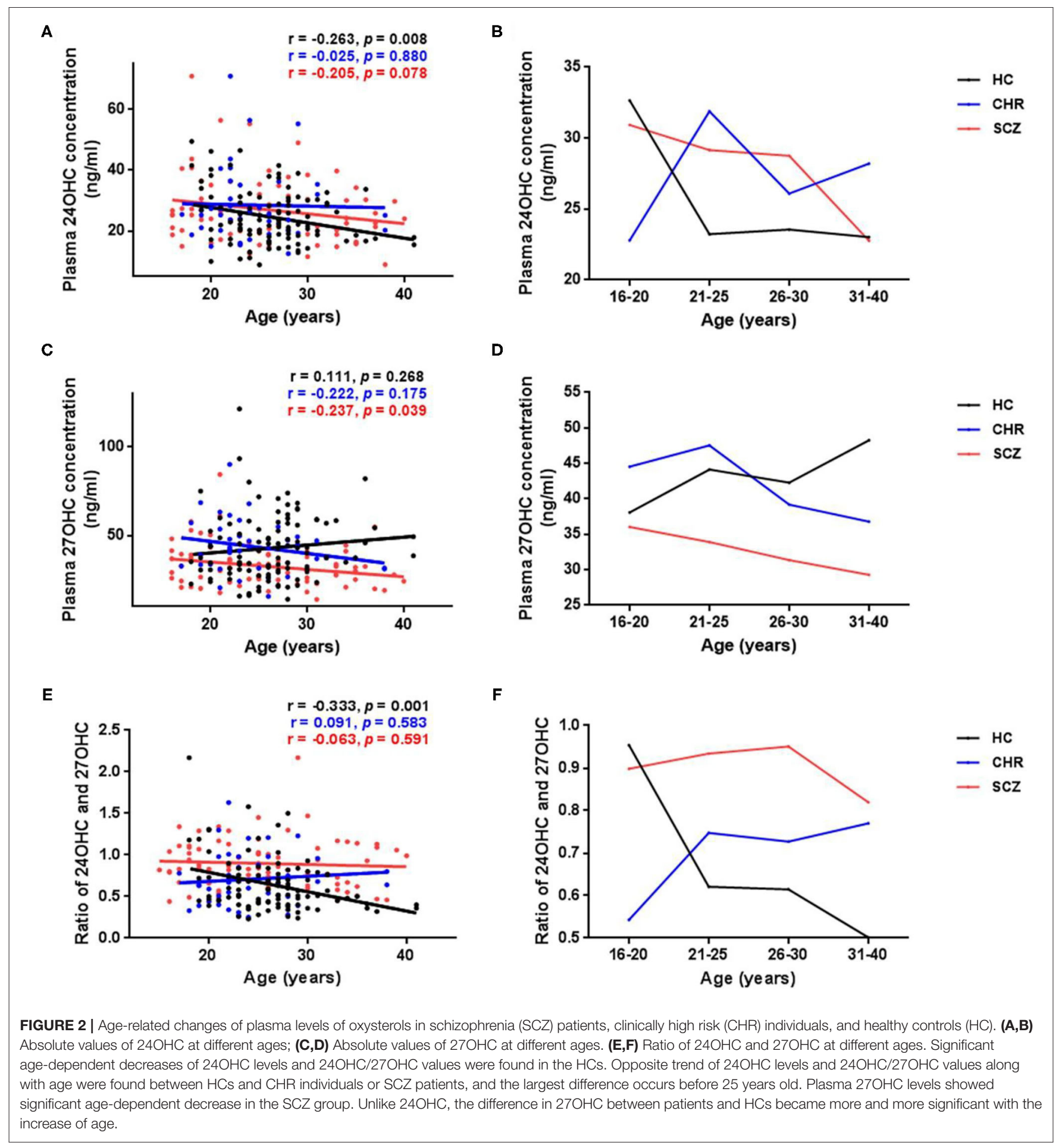

analysis was used in this study (Table 3). There was a significant association between plasma $27 \mathrm{OHC}$ levels and positive symptom scores $(p=0.024)$ in schizophrenia patients. A significant correlation between 24OHC levels and PANSS total scores was found $(p=0.041)$ in schizophrenia patients.

\section{Diagnosis Capacity of Oxysterols in Schizophrenia}

We subsequently performed a ROC curve analysis to assess whether plasma oxysterol levels could differentiate the CHR individuals and schizophrenia patients from HCs (Table 4). The AUC of plasma $24 \mathrm{OHC}$ and $27 \mathrm{OHC}$ diagnosis of schizophrenia 
TABLE 2 | Associations between oxysterols and clinical assessments in schizophrenia patients, CHR individuals, and HCs.

\begin{tabular}{|c|c|c|c|c|c|c|}
\hline & \multicolumn{2}{|c|}{$\mathrm{HC}$} & \multicolumn{2}{|c|}{ CHR } & \multicolumn{2}{|c|}{ SCZ } \\
\hline & $24 \mathrm{OHC}$ & $27 \mathrm{OHC}$ & $240 \mathrm{OHC}$ & $27 \mathrm{OHC}$ & $240 \mathrm{HC}$ & 270HC \\
\hline Total MCCB scores & $0.210(0.186)$ & 0.025 (0.327) & $0.335(0.193)$ & $0.399(-0.169)$ & $0.077(-0.279)$ & $0.778(0.045)$ \\
\hline PANSS positive & - & - & - & - & $0.806(-0.029)$ & $0.010(-0.299)$ \\
\hline PANSS negative & - & - & - & - & $0.029(0.255)$ & $0.621(0.059)$ \\
\hline PANSS general & - & - & - & - & 0.053 (0.228) & $0.587(0.065)$ \\
\hline PANSS total & - & - & - & - & 0.037 (0.244) & $0.659(-0.053)$ \\
\hline
\end{tabular}

Data was shown as p-value (correlation coefficient).

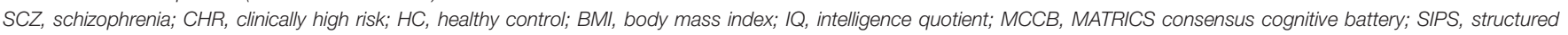
interview for prodromal symptoms; PANSS, Positive and Negative Syndrome Scale; 24OHC, 24(S)-hydroxycholesterol; 27OHC, 27-hydroxycholesterol.

TABLE 3 | Associations between psychiatric symptoms and oxysterols levels in schizophrenia patients.

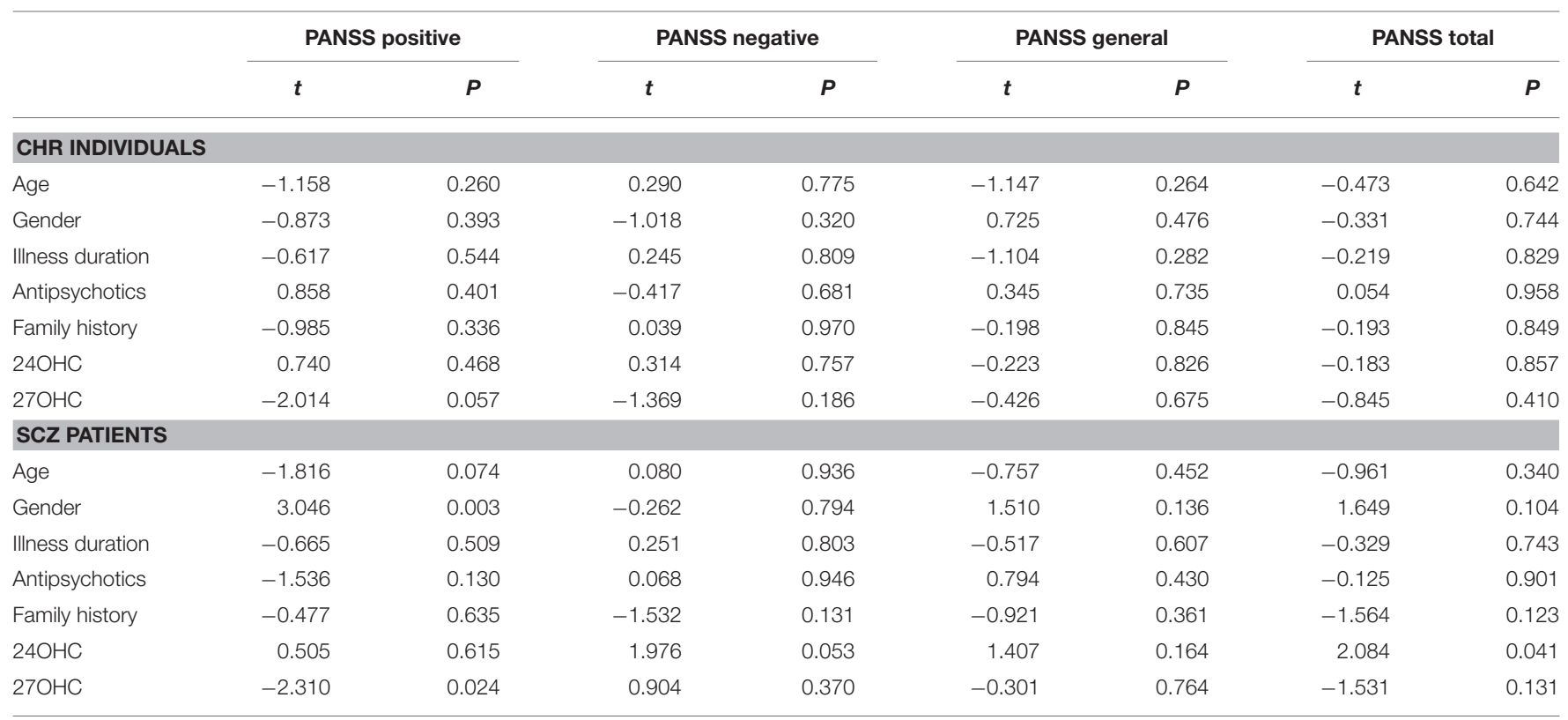

SCZ, schizophrenia; CHR, clinically high risk; PANSS, Positive and Negative Syndrome Scale; 24OHC, 24(S)-hydroxycholesterol; 27OHC, 27-hydroxycholesterol.

patients from the HCs was 0.618 and 0.681 , respectively, and the combination of $24 \mathrm{OHC}$ and $27 \mathrm{OHC}$ was 0.767 . On the other hand, the AUC of plasma $24 \mathrm{OHC}$ and $27 \mathrm{OHC}$ diagnosis of CHR individuals from the HCs was 0.591 and 0.537 , respectively, and the combination of $24 \mathrm{OHC}$ and $27 \mathrm{OHC}$ was 0.592 .

\section{DISCUSSION}

The present study investigated the potential links between plasma levels of tissue-specific cholesterol metabolites and risks of schizophrenia, particularly in schizophrenic patients, CHR subjects, and HCs. First, we found a significant elevation in plasma $24 \mathrm{OHC}$ levels of schizophrenia patients as well as $\mathrm{CHR}$ compared with HCs (Figure 1), although the level of $24 \mathrm{OHC}$ in CHR group compared with $\mathrm{HC}$ did not reach statistical significance. As the most metabolite of cholesterol in brain, large efforts have been made in the previous to unravel the effects of $24 \mathrm{OHC}$ on the brain function. CYP46A1 $1^{-/}$mice showed strong neurological phenotypes in spatial learning and memory deficits, indicating the essential role of $24 \mathrm{OHC}$ in the neuronal function (47). 24OHC has been shown to facilitate the induction of long-term potentiation (LTP) via enhancing NMDA $(21,22,48)$ and tyrosine kinase receptor B (TrkB) signaling $(19,49)$. Moreover, $24 \mathrm{OHC}$ has a positive regulating effect on dendritic spines, enhances synaptic vesicle cycling, and increases the expression of synaptic proteins in synaptosome $(18,20)$. These results implied that increasing $24 \mathrm{OHC}$ levels to facilitate the synaptic transmission might be a therapeutic way for schizophrenia, due to the impairment of synaptic function was the main characteristic of schizophrenia (50). The 24OHC-liked compound reversed schizophrenia-liked behavioral in animal models provides strong evidence for this hypothesis (22). On the other hand, previous studies have been indicated that $24 \mathrm{OHC}$ may facilitate inflammation, oxidative stress, autophagy, and necroptosis, which are also main driving 
TABLE 4 | ROC curve analysis of oxysterols in CHR participants and schizophrenia patients.

\begin{tabular}{lcccc}
\hline & AUC & Sensitivity & Specificity & 95\% Cl \\
\hline CHR individuals & & & & \\
$24 \mathrm{OHC}$ & 0.591 & 0.525 & 0.692 & $0.488-0.695$ \\
$27 \mathrm{OHC}$ & 0.537 & 0.505 & 0.667 & $0.436-0.638$ \\
$24 \mathrm{OHC}$ and $27 \mathrm{OHC}$ & 0.592 & 0.525 & 0.692 & $0.488-0.696$ \\
SCZ patients & & & & \\
$24 \mathrm{OHC}$ & 0.618 & 0.683 & 0.526 & $0.534-0.701$ \\
$27 \mathrm{OHC}$ & 0.681 & 0.485 & 0.842 & $0.603-0.759$ \\
$24 \mathrm{OHC}$ and $27 \mathrm{OHC}$ & 0.767 & 0.782 & 0.671 & $0.697-0.837$ \\
\hline
\end{tabular}

SCZ, schizophrenia; CHR, clinically high risk; $R O C$, receiver operating characteristic; $A \cup C$, area under the ROC curve; Cl, confidence interval; 24OHC, 24(S)-hydroxycholesterol; 27OHC, 27-hydroxycholesterol.

forces in schizophrenia (51-53). These data implied that lowering $24 \mathrm{OHC}$ levels might be a therapeutic way in schizophrenia treatment. Inhibition of CYP46A1 has therapeutic relevance to CNS hyperexcitability supported the therapeutic way of lowering $24 \mathrm{OHC}$ to schizophrenia (54). Hence, the role of $24 \mathrm{OHC}$ is still somewhat puzzling, but a recent report shed a new light that esterification of $24 \mathrm{OHC}$ is a prerequisite for inducing cell death (55). In the present study, our finding on $24 \mathrm{OHC}$ only increased in patients, not enough in $\mathrm{CHR}$, indicating potential risk for schizophrenia. It was noteworthy that whether $24 \mathrm{OHC}$ is an early marker of schizophrenia still needs follow-up study of CHR, due to the conversion rate of CHR to schizophrenia within 2 years was $29.1 \%$ in Chinese sample (56).

To examine the changes of peripheral oxysterol in schizophrenia, we detected the plasma level of $27 \mathrm{OHC}$ in this study. Our results showed a significant reduction of $27 \mathrm{OHC}$ level in schizophrenia patients than HCs (Figure 1), suggesting a disruption of peripheral cholesterol metabolism in schizophrenia. As the most abundant oxysterol in the circulating system, substantial evidence indicates the facilitated effect of $27 \mathrm{OHC}$ on inflammation $(57,58)$, oxidative stress (59), immune suppressive (60), gut microbiota dysbiosis, and intestinal barrier dysfunction (61), all of which were proved to participate in schizophrenia (62-64). On the other hand, $27 \mathrm{OHC}$ is able to pass through the $\mathrm{BBB}$ and may thus contribute to the abnormal brain function. 27OHC not only affects brain function by negatively regulating cholesterol level but also directly had neurotoxic effects on neurite outgrowth and synaptic plasticity $(39-41,65,66)$. Due to the strong correlation between oxysterols and plasma total cholesterol levels (67), the reduced $27 \mathrm{OHC}$ levels in schizophrenia patients in this study might be caused by the decrease of circulating cholesterol concentration, or the increase of degradation to bile acid. In line with our results, lower circulating cholesterol levels in schizophrenia patients than HCs were found in several studies $(9,68-70)$.

Activation of the liver $\mathrm{X}$ receptors (LXRs) was an essential pathway to exert their function of oxystrols, including $24 \mathrm{OHC}$ and 27OHC (71). As the ligands of LXRs, oxysterols could induce cholesterol-related genes expression to regulate the cholesterol transport and elimination. Compared with other oxysterols, $24 \mathrm{OHC}$ was proved to be the most efficient ligand of LXRs (72). Consideration of the opposite changes of the two kinds of oxysterols in schizophrenia patients in our study, one possibility is that elevation of $24 \mathrm{OHC}$ levels might induce the excessive activation of LXRs, while the reduction of $27 \mathrm{OHC}$ levels might not be sufficient to compensate it. It is noteworthy that a significant elevated ratio of $24 \mathrm{OHC}$ and $27 \mathrm{OHC}$ was found in schizophrenia patients in our study, suggesting increased brain/peripheral cholesterol metabolism may be a risk factor for schizophrenia. The shift of balance in $24 \mathrm{OHC}$ and $27 \mathrm{OHC}$ might cause abnormal cholesterol homeostasis and a series of consequences, such as oxidative stress and inflammation $(71,73)$.

As previous studies demonstrated that the level of oxysterol changes with age, $(17,74)$, we analyzed the age-dependent changes in all subjects and found a significant age-dependent decline of 24OHC in HC (Figure 2), not in CHR and schizophrenia groups (Figure 2). Our finding which in line with previous reports $(17,32,74)$ suggested an impaired age-dependent brain-specific cholesterol turnover in CHR and schizophrenia such as the dynamic ratio of brain (synthesis of $24 \mathrm{OHC}$ ) and liver (degradation of $24 \mathrm{OHC}$ ) volumes (74). Similar to $24 \mathrm{OHC}$, as shown in Figure 2, our study showed a different age-dependent change of $27 \mathrm{OHC}$ levels, such as a decline in schizophrenia patients and CHR individuals compared with a slow increase in HCs with aging as previously reported (75-77). These data suggest the disturbance of both $24 \mathrm{OHC}$ and $27 \mathrm{OHC}$ occurring in the prodromal stage of schizophrenia.

Cognitive impairment is one of the major symptoms of schizophrenia, and it is known that oxysterols might affect the cognitive function $(24,78-81)$. In this study, we also found 27OHC showed a significant positive association with cognitive function in HCs (Table 2). The link between oxysterols and cognitive function is confirmed in animal studies, such as both CYP46A1 and CYP27A1 knockout mice showed significant impairment in learning and memory $(47,78,82)$. Extensive evidence showed that the oxysterols regulated cognitive function through several pathways, such as TrkB signaling pathway (18), NMDA receptors $(21,22)$, and nitric oxide signaling (20) to improve synaptic growth and plasticity. However, such positive correlation between oxysterols and cognition was disappeared in schizophrenia patients (Table 2). The possible reason might include the impairment of the signaling pathway which improving synaptic function in schizophrenia $(83,84)$. Whether the disturbed brain and peripheral cholesterol metabolites are the primary or secondary factors in schizophrenia require further investigations.

As the ratio of $24 \mathrm{OHC}$ to $27 \mathrm{OHC}$ is only upregulated in the schizophrenia group compared with the $\mathrm{CHR}$ and $\mathrm{HC}$ groups, we then investigated the association between tissuespecific oxysterols and clinical symptoms in the schizophrenia patients. First, we found that the elevated circulating level of $24 \mathrm{OHC}$ was associated with illness duration in the schizophrenic patients (Table 2). This finding suggested two possibilities at least. One is the increase of brain cholesterol metabolic might be 
correlated with disease progresses in schizophrenia, and another is the deteriorations in peripheral cholesterol homeostasis with the disease duration might be related to antipsychotic treatment in schizophrenia patients $(12,85,86)$. It is believed that most cholesterol (70\%) in the brain is stored in myelin and when myelin or brain cell membrane is damaged, more $24 \mathrm{OHC}$ will be formed from cholesterol $(87,88)$. Indeed, the breakdown of myelin and white matter have been reported in the schizophrenia patients with a long duration of illness (89), while others also found impaired white matter at early stage of schizophrenia (9092). These reports support our first hypothesis that the elevated $24 \mathrm{OHC}$ may be related to the progressive pathophysiology, such as abnormalities of myelin in schizophrenia. Interestingly enough, similar changes of plasma $24 \mathrm{OHC}$ levels were also reported in ASD and MDD which shared the similar myelin or synaptic function defect as schizophrenia $(28,29,93-96)$. All together prompt a critical role of brain-specific originated oxysterol in neuropathology of psychiatric disorders.

To see whether antipsychotic treatment might be involved in the changes of oxysterol levels in schizophrenia patients, we analyzed the association between oxysterols and treatments. We found no significant differences in $27 \mathrm{OHC}$ levels in schizophrenia patients who treated with and without antipsychotics (Supplementary Figure 1, $p=0.905$ ). Our data suggest no significant impact of antipsychotics in plasma $27 \mathrm{OHC}$ levels. Similarly, we found no evidence of antipsychotics effected on plasma 24OHC levels in schizophrenia patients (Supplementary Figure 1, $p=0.995$ ), which was consistent with previous report [Chiappelli et al., (32)]. These results suggest that the association between elevated circulating $24 \mathrm{OHC}$ levels with illness duration in the schizophrenic patients is more likely due to the neuropathological progress of the disease and preferable feather of oxysterols as potential biomarker in schizophrenia.

To examine whether oxysterols levels were associated with psychiatric symptoms, we then investigated the correlation between circulating $24 \mathrm{OHC}$ and $27 \mathrm{OHC}$ and positive and negative symptoms scales (PANSS) scores in the schizophrenic patients. First, we found that $24 \mathrm{OHC}$ levels positively correlated with total PANSS and negative symptom scores (Tables 2, 3). As accumulating evidence revealed the negative symptoms were related with disturbance in serotonin and glutamate transmission (97-99), which can be regulated by 24OHCinduced disequilibrium of cholesterol homeostasis in the brain through lipid raft microdomains on the cell membranes $(100,101)$, we hypothesize that the correlation of $24 \mathrm{OHC}$ to negative symptoms in schizophrenia might be mediated through serotonin signaling. In addition, $24 \mathrm{OHC}$ as an allosteric regulator of NMDA receptor can increase the glutamatergic signaling transmission which also aggravates the excitotoxic injury in schizophrenia $(20-22,102)$. On the other hand, our present study also showed an inverse correlation between $27 \mathrm{OHC}$ levels and positive symptom scores in schizophrenia patients (Tables 2, 3). As positive symptoms were associated with increased hyperdopaminergic activity in schizophrenia $(103,104), 27 \mathrm{OHC}$ as a selective estrogen receptor modulator can attenuate dopamine level by reducing the expression of tyrosine hydroxylase ( $\mathrm{TH}$, the rate-limiting enzyme in dopamine synthesis) via the inhibition of estrogen signaling (105-107).

However, whether oxysterols could be potential biomarkers for schizophrenia still needs more advanced investigation. For example, a recent study from Chiappelli et al. based a large sample (226 schizophrenia patients and 204 controls) found no significant difference in plasma $24 \mathrm{OHC}$ levels between patients and controls (32). Furthermore, they also found no relation between plasma $24 \mathrm{OHC}$ levels and whole-brain white matter average fractional anisotropy or cortical thickness (32). While the report from this study is not consistent with our hypothesis that the elevation of $24 \mathrm{OHC}$ was associated with brain structure, it is important to notice that the change of plasma $24 \mathrm{OHC}$ levels in the psychiatric disease might have brain regional specificity. For example, a postmortem study of suicide samples (mainly from MDD patients) showed elevated 24OHC levels in the prefrontal cortex (28), while another report indicated no significant change in $24 \mathrm{OHC}$ levels was found in association cortex (108). The lack of assessment of sub-brain structural abnormalities in schizophrenia patients left open the question whether the elevation of $24 \mathrm{OHC}$ was associated with regional brain structure.

Several limitations were found in this study. First, 30\% schizophrenia patients were antipsychotic-treated individuals. Although we found no effect of antipsychotic treatment on 27OHC levels (Supplementary Figure 1), we could not exclude the possible confounding effect of medications on cognitive function and clinical symptoms in our study. Second, the plasma total cholesterol levels were not detected in this study. Third, the lack of the follow-up of CHR participants left open the question if plasma oxysterol levels changed with the progress and outcome of schizophrenia.

Taken together, our study indicated the elevation of circulating $24 \mathrm{OHC}$ levels and the reduction of $27 \mathrm{OHC}$ levels in schizophrenia patients, and this alteration were related to the severity of psychiatric symptoms in schizophrenia. This suggested that plasma oxysterols might be the potential biomarker in schizophrenia.

\section{DATA AVAILABILITY STATEMENT}

The raw data supporting the conclusions of this article will be made available by the authors, without undue reservation.

\section{ETHICS STATEMENT}

The studies involving human participants were reviewed and approved by Independent Ethics Committee (IEC) of the Beijing Anding Hospital, Capital Medical University, China. Written informed consent to participate in this study was provided by the participants' legal guardian/next of kin.

\section{AUTHOR CONTRIBUTIONS}

CW, RL, and TJ obtained funding for this study. ZS, RL, and CW designed the research. ZS, LZ, QB, ZM, YH, and YL performed 
the experiments and statistical analysis. ZS and RL wrote the manuscript. All authors contributed to the article and approved the submitted version.

\section{FUNDING}

This work was supported by the National Natural Science Foundation of China (81971250 and 91849103), Beijing Municipal Administration of Hospitals Clinical Medicine Development of Special Funding Support (ZYLX201807), Beijing Municipal Natural Science Foundation (7192081), and National Science and Technology Major Project of China (2018ZX09201014).

\section{REFERENCES}

1. Rund BR. The research evidence for schizophrenia as a neurodevelopmental disorder. Scand J Psychol. (2018) 59:49-58. doi: 10.1111/sjop.12414

2. Lingwood D, Simons K. Lipid rafts as a membrane-organizing principle. Science. (2010) 327:46-50. doi: 10.1126/science.1174621

3. Petrov AM, Kasimov MR, Zefirov AL. Brain cholesterol metabolism and its defects: linkage to neurodegenerative diseases and synaptic dysfunction. Acta Naturae. (2016) 8:58-73. doi: 10.32607/20758251-2016-8-1-58-73

4. Rosello-Busquets C, de la Oliva N, Martinez-Marmol R, Hernaiz-Llorens M, Pascual M, Muhaisen A, et al. Cholesterol depletion regulates axonal growth and enhances central and peripheral nerve regeneration. Front Cell Neurosci. (2019) 13:40. doi: 10.3389/fncel.2019.00040

5. Ertugrul G, Yankol Y, Mecit N, Kirimlioglu H, Kanmaz T, Acarli K, et al. Liver transplant and improvements in cholesterol biosynthesis defects: a case report of Smith-Lemli-Opitz syndrome. Exp Clin Transplant. (2019). doi: 10.6002/ect.2018.0131. [Epub ahead of print].

6. Genaro-Mattos TC, Allen LB, Anderson A, Tallman KA, Porter NA, Korade $\mathrm{Z}$, et al. Maternal aripiprazole exposure interacts with 7-dehydrocholesterol reductase mutations and alters embryonic neurodevelopment. Mol Psychiatry. (2019) 24:491-500. doi: 10.1038/s41380-019-0368-6

7. Kanungo S, Soares N, He M, Steiner RD. Sterol metabolism disorders and neurodevelopment-an update. Dev Disabil Res Rev. (2013) 17:197210. doi: 10.1002/ddrr.1114

8. Devanarayanan S, Nandeesha H, Kattimani S, Sarkar S, Jose J. Elevated copper, hs C-reactive protein and dyslipidemia in drug free schizophrenia: relation with psychopathology score. Asian J Psychiatr. (2016) 24:99102. doi: 10.1016/j.ajp.2016.08.025

9. Kavoor AR, Mitra S, Kumar S, Sisodia AK, Jain R. Lipids, aggression, suicidality and impulsivity in drug-naive/drug-free patients of schizophrenia. Asian J Psychiatr. (2017) 27:12936. doi: 10.1016/j.ajp.2017.03.002

10. Solberg DK, Bentsen H, Refsum H, Andreassen OA. Association between serum lipids and membrane fatty acids and clinical characteristics in patients with schizophrenia. Acta Psychiatr Scand. (2015) 132:293300. doi: 10.1111/acps.12388

11. Kim DD, Barr AM, Fredrikson DH, Honer WG, Procyshyn RM. Association between serum lipids and antipsychotic response in schizophrenia. Curr Neuropharmacol. (2019) 17:852-60. doi: 10.2174/1570159X17666190228113348

12. Rummel-Kluge C, Komossa K, Schwarz S, Hunger H, Schmid F, Lobos $\mathrm{CA}$, et al. Head-to-head comparisons of metabolic side effects of second generation antipsychotics in the treatment of schizophrenia: a systematic review and meta-analysis. Schizophr Res. (2010) 123:225-33. doi: 10.1016/j.schres.2010.07.012

13. Bjorkhem I. Crossing the barrier: oxysterols as cholesterol transporters and metabolic modulators in the brain. J Intern Med. (2006) 260:493508. doi: 10.1111/j.1365-2796.2006.01725.x

\section{ACKNOWLEDGMENTS}

The authors are grateful to all study participants in this study.

\section{SUPPLEMENTARY MATERIAL}

The Supplementary Material for this article can be found online at: https://www.frontiersin.org/articles/10.3389/fpsyt. 2021.711734/full\#supplementary-material

Supplementary Figure 1 | Differences in plasma oxysterol levels between antipsychotic-naive and antipsychotic-treated patients with schizophrenia. The plasma $24 \mathrm{OHC}$ levels and $27 \mathrm{OHC}$ levels in antipsychotic-naive or antipsychotic-treated patients with schizophrenia are shown in (A,B), respectively. No significant difference was found between these two groups in patients.

14. Iuliano L, Crick PJ, Zerbinati C, Tritapepe L, Abdel-Khalik J, Poirot M, et al. Cholesterol metabolites exported from human brain. Steroids. (2015) 99:189-93. doi: 10.1016/j.steroids.2015.01.026

15. Leoni V. Oxysterols as markers of neurological disease-a review. Scand J Clin Lab Invest. (2009) 69:22-5. doi: 10.1080/00365510802651858

16. Lutjohann D, von Bergmann K. 24S-hydroxycholesterol: a marker of brain cholesterol metabolism. Pharmacopsychiatry. (2003) 36(Suppl 2):S1026. doi: 10.1055/s-2003-43053

17. Lutjohann D, Breuer O, Ahlborg G, Nennesmo I, Siden A, Diczfalusy U, et al. Cholesterol homeostasis in human brain: evidence for an age-dependent flux of 24S-hydroxycholesterol from the brain into the circulation. Proc Natl Acad Sci USA. (1996) 93:9799-804. doi: 10.1073/pnas.93.18.9799

18. Moutinho M, Nunes MJ, Correia JC, Gama MJ, Castro-Caldas M, CedazoMinguez A, et al. Neuronal cholesterol metabolism increases dendritic outgrowth and synaptic markers via a concerted action of GGTase-I and Trk. Sci Rep. (2016) 6:30928. doi: 10.1038/srep30928

19. Martin MG, Perga S, Trovo L, Rasola A, Holm P, Rantamaki T, et al. Cholesterol loss enhances TrkB signaling in hippocampal neurons aging in vitro. Mol Biol Cell. (2008) 19:2101-12. doi: 10.1091/mbc.e07-09-0897

20. Kasimov MR, Fatkhrakhmanova MR, Mukhutdinova KA, Petrov AM. 24S-Hydroxycholesterol enhances synaptic vesicle cycling in the mouse neuromuscular junction: implication of glutamate NMDA receptors and nitric oxide. Neuropharmacology. (2017) 117:61-73. doi: 10.1016/j.neuropharm.2017.01.030

21. Sun MY, Izumi Y, Benz A, Zorumski CF, Mennerick S. Endogenous 24Shydroxycholesterol modulates NMDAR-mediated function in hippocampal slices. J Neurophysiol. (2016) 115:1263-72. doi: 10.1152/jn.00890.2015

22. Paul SM, Doherty JJ, Robichaud AJ, Belfort GM, Chow BY, Hammond RS, et al. The major brain cholesterol metabolite $24(\mathrm{~S})$-hydroxycholesterol is a potent allosteric modulator of N-methyl-D-aspartate receptors. J Neurosci. (2013) 33:17290-300. doi: 10.1523/JNEUROSCI.2619-13.2013

23. Zarrouk A, Debbabi M, Bezine M, Karym EM, Badreddine A, Rouaud O, et al. Lipid biomarkers in Alzheimer's disease. Curr Alzheimer Res. (2018) 15:303-12. doi: 10.2174/1567205014666170505101426

24. Loera-Valencia R, Goikolea J, Parrado-Fernandez C, Merino-Serrais P, Maioli S. Alterations in cholesterol metabolism as a risk factor for developing Alzheimer's disease: potential novel targets for treatment. J Steroid Biochem Mol Biol. (2019) 190:104-14. doi: 10.1016/j.jsbmb.2019.03.003

25. Zarrouk A, Vejux A, Mackrill J, O'Callaghan Y, Hammami M, O’Brien N, et al. Involvement of oxysterols in age-related diseases and ageing processes. Ageing Res Rev. (2014) 18:148-62. doi: 10.1016/j.arr.2014.09.006

26. Vejux A, Namsi A, Nury T, Moreau T, Lizard G. Biomarkers of amyotrophic lateral sclerosis: current status and interest of oxysterols and phytosterols. Front Mol Neurosci. (2018) 11:12. doi: 10.3389/fnmol.2018.00012

27. Di Natale C, Monaco A, Pedone C, Tessitore A, De Mase A, Tedeschi $\mathrm{G}$, et al. The level of 24-hydroxycholesteryl esters decreases in plasma of patients with Parkinson's disease. Neurosci Lett. (2018) 672:10812. doi: 10.1016/j.neulet.2018.02.041 
28. Freemantle E, Chen GG, Cruceanu C, Mechawar N, Turecki G. Analysis of oxysterols and cholesterol in prefrontal cortex of suicides. Int $J$ Neuropsychopharmacol. (2013) 16:1241-9. doi: 10.1017/S1461145712001587

29. Grayaa S, Zerbinati C, Messedi M, HadjKacem I, Chtourou M, Ben Touhemi $\mathrm{D}$, et al. Plasma oxysterol profiling in children reveals 24-hydroxycholesterol as a potential marker for Autism Spectrum Disorders. Biochimie. (2018) 153:80-85. doi: 10.1016/j.biochi.2018.04.026

30. Wang D, Sun X, Yan J, Ren B, Cao B, Lu Q, et al. Alterations of eicosanoids and related mediators in patients with schizophrenia. J Psychiatr Res. (2018) 102:168-78. doi: 10.1016/j.jpsychires.2018.04.002

31. Muguruza C, Morentin B, Meana JJ, Alexander SP, Callado LF. Endocannabinoid system imbalance in the postmortem prefrontal cortex of subjects with schizophrenia. J Psychopharmacol. (2019) 33:1132-40. doi: 10.1177/0269881119857205

32. Chiappelli J, Quinton MS, Volfson D, Cwik M, Marshall W, Bruce $\mathrm{H}$, et al. Assessment of brain cholesterol metabolism biomarker 24S-hydroxycholesterol in schizophrenia. NPJ Schizophr. (2020) 6:34. doi: 10.1038/s41537-020-00121-4

33. Brooks SW, Dykes AC, Schreurs BG. A high-cholesterol diet increases 27-hydroxycholesterol and modifies estrogen receptor expression and neurodegeneration in rabbit hippocampus. J Alzheimers Dis. (2017) 56:18596. doi: 10.3233/JAD-160725

34. Zarrouk A, Hammouda S, Ghzaiel I, Hammami S, Khamlaoui W, Ahmed $\mathrm{SH}$, et al. Association between oxidative stress and altered cholesterol metabolism in Alzheimer's disease patients. Curr Alzheimer Res. (2020) 17:823-34. doi: 10.2174/1567205017666201203123046

35. Zhang DD, Yu HL, Ma WW, Liu QR, Han J, Wang H, et al. 27Hydroxycholesterol contributes to disruptive effects on learning and memory by modulating cholesterol metabolism in the rat brain. Neuroscience. (2015) 300:163-73. doi: 10.1016/j.neuroscience.2015.05.022

36. Liu Q, An Y, Yu H, Lu Y, Feng L, Wang C, et al. Relationship between oxysterols and mild cognitive impairment in the elderly: a case-control study. Lipids Health Dis. (2016) 15:177. doi: 10.1186/s12944-016-0344-y

37. Mateos L, Ismail MA, Gil-Bea FJ, Leoni V, Winblad B, Bjorkhem I, et al. Upregulation of brain renin angiotensin system by 27 hydroxycholesterol in Alzheimer's disease. J Alzheimers Dis. (2011) 24:66979. doi: 10.3233/JAD-2011-101512

38. Sandebring-Matton A, Goikolea J, Bjorkhem I, Paternain L, Kemppainen N, Laatikainen T, et al. 27-Hydroxycholesterol, cognition, and brain imaging markers in the FINGER randomized controlled trial. Alzheimers Res Ther. (2021) 13:56. doi: 10.1186/s13195-021-00790-y

39. Wang Y, An Y, Zhang D, Yu H, Zhang X, Wang Y, et al. 27Hydroxycholesterol alters synaptic structural and functional plasticity in hippocampal neuronal cultures. J Neuropathol Exp Neurol. (2019) 78:23847. doi: 10.1093/jnen/nlz002

40. Merino-Serrais P, Loera-Valencia R, Rodriguez-Rodriguez P, ParradoFernandez C, Ismail MA, Maioli S, et al. 27-Hydroxycholesterol induces aberrant morphology and synaptic dysfunction in hippocampal neurons. Cereb Cortex. (2019) 29:429-46. doi: 10.1093/cercor/bhy274

41. Loera-Valencia R, Vazquez-Juarez E, Munoz A, Gerenu G, Gomez-Galan M, Lindskog M, et al. High levels of 27-hydroxycholesterol results in synaptic plasticity alterations in the hippocampus. Sci Rep. (2021) 11:3736. doi: 10.1038/s41598-021-83008-3

42. Miller TJ, McGlashan TH, Rosen JL, Cadenhead K, Cannon T, Ventura J, et al. Prodromal assessment with the structured interview for prodromal syndromes and the scale of prodromal symptoms: predictive validity, interrater reliability, and training to reliability. Schizophr Bull. (2003) 29:70315. doi: 10.1093/oxfordjournals.schbul.a007040

43. Kay SR, Fiszbein A, Opler LA. The positive and negative syndrome scale (PANSS) for schizophrenia. Schizophr Bull. (1987) 13:261-76. doi: 10.1093/schbul/13.2.261

44. Shi C, Kang L, Yao S, Ma Y, Li T, Liang Y, et al. The MATRICS consensus cognitive battery (MCCB): co-norming and standardization in China. Schizophr Res. (2015) 169:109-15. doi: 10.1016/j.schres.2015.09.003

45. Dai XY, Ryan JJ, Paolo AM, Harrington RG. Factor analysis of the mainland Chinese version of the Wechsler Adult Intelligence Scale (WAIS-RC) in a brain-damaged sample. Int J Neurosci. (1990) 55:10711. doi: $10.3109 / 00207459008985956$
46. Burkard I, Rentsch KM, von Eckardstein A. Determination of 24S- and 27-hydroxycholesterol in plasma by high-performance liquid chromatography-mass spectrometry. J Lipid Res. (2004) 45:776-81. doi: 10.1194/jlr.D300036-JLR200

47. Kotti TJ, Ramirez DM, Pfeiffer BE, Huber KM, Russell DW. Brain cholesterol turnover required for geranylgeraniol production and learning in mice. Proc Natl Acad Sci USA. (2006) 103:3869-74. doi: 10.1073/pnas.0600316103

48. Sun MY, Taylor A, Zorumski CF, Mennerick S. 24S-hydroxycholesterol and 25-hydroxycholesterol differentially impact hippocampal neuronal survival following oxygen-glucose deprivation. PLoS ONE. (2017) 12:e174416. doi: 10.1371/journal.pone.0174416

49. Kacher R, Lamaziere A, Heck N, Kappes V, Mounier C, Despres G, et al. CYP46A1 gene therapy deciphers the role of brain cholesterol metabolism in Huntington's disease. Brain. (2019) 142:2432-50. doi: 10.1093/brain/awz174

50. Owen MJ, Sawa A, Mortensen PB. Schizophrenia. Lancet. (2016) 388:8697. doi: 10.1016/S0140-6736(15)01121-6

51. Noguchi N, Saito Y, Urano Y. Diverse functions of 24(S)hydroxycholesterol in the brain. Biochem Biophys Res Commun. (2014) 446:692-6. doi: 10.1016/j.bbrc.2014.02.010

52. Alexandrov P, Cui JG, Zhao Y, Lukiw WJ. 24S-hydroxycholesterol induces inflammatory gene expression in primary human neural cells. Neuroreport. (2005) 16:909-13. doi: 10.1097/00001756-200506210-00007

53. Nobrega C, Conceicao A, Costa RG, Koppenol R, Sequeira RL, Nunes R, et al. The cholesterol 24-hydroxylase activates autophagy and decreases mutant huntingtin build-up in a neuroblastoma culture model of Huntington's disease. BMC Res Notes. (2020) 13:210. doi: 10.1186/s13104-020-05053-X

54. Nishi T, Kondo S, Miyamoto M, Watanabe S, Hasegawa S, Kondo S, et al. Soticlestat, a novel cholesterol 24-hydroxylase inhibitor shows a therapeutic potential for neural hyperexcitation in mice. Sci Rep. (2020) 10:17081. doi: 10.1038/s41598-020-74036-6

55. Yamanaka K, Urano Y, Takabe W, Saito Y, Noguchi N. Induction of apoptosis and necroptosis by 24(S)-hydroxycholesterol is dependent on activity of acyl-CoA:cholesterol acyltransferase 1. Cell Death Dis. (2014) 5:e990. doi: 10.1038/cddis.2013.524

56. Zhang TH, Li HJ, Woodberry KA, Xu LH, Tang YY, Guo Q, et al. Two-year follow-up of a Chinese sample at clinical high risk for psychosis: timeline of symptoms, help-seeking and conversion. Epidemiol Psychiatr Sci. (2017) 26:287-98. doi: 10.1017/S2045796016000184

57. Gargiulo S, Gamba P, Testa G, Rossin D, Biasi F, Poli G, et al. Relation between TLR4/NF-kappaB signaling pathway activation by 27hydroxycholesterol and 4-hydroxynonenal, and atherosclerotic plaque instability. Aging Cell. (2015) 14:569-81. doi: 10.1111/acel.12322

58. Asghari A, Ishikawa T, Hiramitsu S, Lee WR, Umetani J, Bui L, et al. 27-Hydroxycholesterol promotes adiposity and mimics adipogenic diet-induced inflammatory signaling. Endocrinology. (2019) 160:248594. doi: 10.1210/en.2019-00349

59. Dasari B, Prasanthi JR, Marwarha G, Singh BB, Ghribi O. The oxysterol 27-hydroxycholesterol increases beta-amyloid and oxidative stress in retinal pigment epithelial cells. BMC Ophthalmol. (2010) 10:22. doi: 10.1186/1471-2415-10-22

60. Baek AE, Yu YA, He S, Wardell SE, Chang CY, Kwon S, et al. The cholesterol metabolite 27 hydroxycholesterol facilitates breast cancer metastasis through its actions on immune cells. Nat Commun. (2017) 8:864. doi: 10.1038/s41467-017-00910-Z

61. Wang Y, An Y, Ma W, Yu H, Lu Y, Zhang X, et al. 27-Hydroxycholesterol contributes to cognitive deficits in APP/PS1 transgenic mice through microbiota dysbiosis and intestinal barrier dysfunction. J Neuroinflammation. (2020) 17:199. doi: 10.1186/s12974-020-01873-7

62. Yuan X, Kang Y, Zhuo C, Huang XF, Song X. The gut microbiota promotes the pathogenesis of schizophrenia via multiple pathways. Biochem Biophys Res Commun. (2019) 512:373-80. doi: 10.1016/j.bbrc.2019.02.152

63. Muller $\mathrm{N}$. Inflammation in schizophrenia: pathogenetic aspects and therapeutic considerations. Schizophr Bull. (2018) 44:97382. doi: $10.1093 /$ schbul/sby024

64. Mongan D, Ramesar M, Focking M, Cannon M, Cotter D. Role of inflammation in the pathogenesis of schizophrenia: a review of the evidence, proposed mechanisms and implications for treatment. Early Interv Psychiatry. (2020) 14:385-97. doi: 10.1111/eip.12859 
65. An Y, Zhang DD, Yu HL, Ma WW, Lu YH, Liu QR, et al. 27-Hydroxycholesterol regulates cholesterol synthesis and transport in C6 glioma cells. Neurotoxicology. (2017) 59:88-97. doi: 10.1016/j.neuro.2017.02.001

66. Wang $\mathrm{Y}$, Zhang X, Wang T, Liu W, Wang L, Hao L, et al. 27Hydroxycholesterol promotes the transfer of astrocyte-derived cholesterol to neurons in co-cultured SH-SY5Y cells and C6 cells. Front Cell Dev Biol. (2020) 8:580599. doi: 10.3389/fcell.2020.580599

67. Burkard I, von Eckardstein A, Waeber G, Vollenweider P, Rentsch KM. Lipoprotein distribution and biological variation of 24S- and 27hydroxycholesterol in healthy volunteers. Atherosclerosis. (2007) 194:718. doi: 10.1016/j.atherosclerosis.2006.09.026

68. Kumar M, Sidana A. Clozapine-induced acute hypertriglyceridemia. Indian J Psychol Med. (2017) 39:682-4. doi: 10.4103/0253-7176.217031

69. Mensi R, Messaoud A, Mhallah A, Azizi I, Salah WH, Douki W, et al. The association between altered lipid profile and suicide attempt among Tunisian patients with schizophrenia. Ann Gen Psychiatry. (2016) 15:36. doi: 10.1186/s12991-016-0123-1

70. Roy S, Dasgupta A, Banerjee U, Chowdhury P, Mukhopadhyay A, Saha G, et al. Role of membrane cholesterol and lipid peroxidation in regulating the $\mathrm{Na}(+) / \mathrm{K}(+)$-ATPase activity in schizophrenia. Indian J Psychiatry. (2016) 58:317-25. doi: 10.4103/0019-5545.192023

71. Mouzat K, Chudinova A, Polge A, Kantar J, Camu W, Raoul $\mathrm{C}$, et al. Regulation of brain cholesterol: what role do liver $\mathrm{x}$ receptors play in neurodegenerative diseases? Int J Mol Sci. (2019) 20:3858. doi: 10.3390/ijms20163858

72. Janowski BA, Grogan MJ, Jones SA, Wisely GB, Kliewer SA, Corey EJ, et al. Structural requirements of ligands for the oxysterol liver X receptors LXRalpha and LXRbeta. Proc Natl Acad Sci USA. (1999) 96:26671. doi: $10.1073 /$ pnas.96.1.266

73. Schulman IG. Liver $\mathrm{X}$ receptors link lipid metabolism and inflammation. FEBS Lett. (2017) 591:2978-91. doi: 10.1002/1873-3468.12702

74. Bjorkhem I, Starck L, Andersson U, Lutjohann D, von Bahr S, Pikuleva I, et al. Oxysterols in the circulation of patients with the Smith-Lemli-Opitz syndrome: abnormal levels of 24S- and 27-hydroxycholesterol. J Lipid Res. (2001) 42:366-71. doi: 10.1016/S0022-2275(20)31660-6

75. He S, Nelson ER. 27-Hydroxycholesterol, an endogenous selective estrogen receptor modulator. Maturitas. (2017) 104:29-35. doi: 10.1016/j.maturitas.2017.07.014

76. Le Cornet C, Johnson TS, Lu DL, Kaaks R, Fortner RT. Association between lifestyle, dietary, reproductive, and anthropometric factors and circulating 27-hydroxycholesterol in EPIC-Heidelberg. Cancer Causes Control. (2020) 31:181-92. doi: 10.1007/s10552-019-01259-y

77. Sosic-Jurjevic B, Lutjohann D, Jaric I, Miler M, Vojnovic Milutinovic D, Filipovic B, et al. Effects of age and soybean isoflavones on hepatic cholesterol metabolism and thyroid hormone availability in acyclic female rats. Exp Gerontol. (2017) 92:74-81. doi: 10.1016/j.exger.2017. 03.016

78. Djelti F, Braudeau J, Hudry E, Dhenain M, Varin J, Bieche I, et al. CYP46A1 inhibition, brain cholesterol accumulation and neurodegeneration pave the way for Alzheimer's disease. Brain. (2015) 138:2383-98. doi: 10.1093/brain/awv166

79. Hughes TM, Rosano C, Evans RW, Kuller LH. Brain cholesterol metabolism, oxysterols, and dementia. J Alzheimers Dis. (2013) 33:891911. doi: 10.3233/JAD-2012-121585

80. Wang HL, Wang YY, Liu XG, Kuo SH, Liu N, Song QY, et al. Cholesterol, 24Hydroxycholesterol, and 27-Hydroxycholesterol as surrogate biomarkers in cerebrospinal fluid in mild cognitive impairment and Alzheimer's disease: a meta-analysis. J Alzheimers Dis. (2016) 51:45-55. doi: 10.3233/JAD150734

81. Zhang X, Lv C, An Y, Liu Q, Rong H, Tao L, et al. Increased levels of 27-hydroxycholesterol induced by dietary cholesterol in brain contribute to learning and memory impairment in rats. Mol Nutr Food Res. (2018) 62. doi: 10.1002/mnfr.201700531. [Epub ahead of print].

82. Heverin M, Maioli S, Pham T, Mateos L, Camporesi E, Ali Z, et al. 27-hydroxycholesterol mediates negative effects of dietary cholesterol on cognition in mice. Behav Brain Res. (2015) 278:356-9. doi: 10.1016/j.bbr.2014.10.018
83. Di Carlo P, Punzi G, Ursini G. Brain-derived neurotrophic factor and schizophrenia. Psychiatr Genet. (2019) 29:20010. doi: 10.1097/YPG.0000000000000237

84. Nakazawa K, Sapkota K. The origin of NMDA receptor hypofunction in schizophrenia. Pharmacol Ther. (2020) 205:107426. doi: 10.1016/j.pharmthera.2019.107426

85. Martinez-Andres JA, Garcia-Carmona JA. Switching from clozapine to paliperidone palmitate-3-monthly improved obesity, hyperglycemia and dyslipidemia lowering antipsychotic dose equivalents in a treatmentresistant schizophrenia cohort. Int Clin Psychopharmacol. (2019) 35:1639. doi: 10.1097/YIC.0000000000000300

86. Pillinger $\mathrm{T}$, McCutcheon RA, Vano L, Mizuno Y, Arumuham A, Hindley G, et al. Comparative effects of 18 antipsychotics on metabolic function in patients with schizophrenia, predictors of metabolic dysregulation, and association with psychopathology: a systematic review and network meta-analysis. Lancet Psychiatry. (2020) 7:64-77. doi: 10.1016/S2215-0366(19)30416-X

87. Fellows Maxwell K, Bhattacharya S, Bodziak ML, Jakimovski D, Hagemeier J, Browne RW, et al. Oxysterols and apolipoproteins in multiple sclerosis: a 5 year follow-up study. J Lipid Res. (2019) 60:1190-8. doi: 10.1194/jlr.M089664

88. van de Kraats C, Killestein J, Popescu V, Rijkers E, Vrenken H, Lutjohann D, et al. Oxysterols and cholesterol precursors correlate to magnetic resonance imaging measures of neurodegeneration in multiple sclerosis. Mult Scler. (2014) 20:412-7. doi: 10.1177/1352458513499421

89. Marui T, Torii Y, Iritani S, Sekiguchi H, Habuchi C, Fujishiro H, et al. The neuropathological study of myelin oligodendrocyte glycoprotein in the temporal lobe of schizophrenia patients. Acta Neuropsychiatr. (2018) 30:232-40. doi: 10.1017/neu.2018.6

90. Cropley VL, Klauser P, Lenroot RK, Bruggemann J, Sundram $\mathrm{S}$, Bousman $\mathrm{C}$, et al. Accelerated gray and white matter deterioration with age in schizophrenia. Am J Psychiatry. (2017) 174:286-95. doi: 10.1176/appi.ajp.2016.16050610

91. Francis AN, Bhojraj TS, Prasad KM, Montrose D, Eack SM, Rajarethinam R, et al. Alterations in the cerebral white matter of genetic high risk offspring of patients with schizophrenia spectrum disorder. Prog Neuropsychopharmacol Biol Psychiatry. (2013) 40:187-92. doi: 10.1016/j.pnpbp.2012.08.003

92. Zeng B, Ardekani BA, Tang Y, Zhang T, Zhao S, Cui H, et al. Abnormal white matter microstructure in drug-naive first episode schizophrenia patients before and after eight weeks of antipsychotic treatment. Schizophr Res. (2016) 172:1-8. doi: 10.1016/j.schres.2016.01.051

93. Swanson MR, Hazlett HC. White matter as a monitoring biomarker for neurodevelopmental disorder intervention studies. J Neurodev Disord. (2019) 11:33. doi: 10.1186/s11689-019-9295-8

94. Wang Y, Olson IR. The original social network: white matter and social cognition. Trends Cogn Sci. (2018) 22:504-16. doi: 10.1016/j.tics.2018.03.005

95. Menard C, Hodes GE, Russo SJ. Pathogenesis of depression: insights from human and rodent studies. Neuroscience. (2016) 321:138-62. doi: 10.1016/j.neuroscience.2015.05.053

96. Cartocci V, Catallo M, Tempestilli M, Segatto M, Pfrieger FW, Bronzuoli $\mathrm{MR}$, et al. Altered brain cholesterol/isoprenoid metabolism in a rat model of autism spectrum disorders. Neuroscience. (2018) 372:2737. doi: 10.1016/j.neuroscience.2017.12.053

97. Curic S, Leicht G, Thiebes S, Andreou C, Polomac N, Eichler IC, et al. Reduced auditory evoked gamma-band response and schizophrenia-like clinical symptoms under subanesthetic ketamine. Neuropsychopharmacology. (2019) 44:1239-46. doi: 10.1038/s41386-019-0328-5

98. Strauss GP, Nunez A, Ahmed AO, Barchard KA, Granholm E, Kirkpatrick $\mathrm{B}$, et al. The latent structure of negative symptoms in schizophrenia. JAMA Psychiatry. (2018) 75:1271-9. doi: 10.1001/jamapsychiatry.2018.2475

99. Tang H, Dalton CF, Srisawat U, Zhang ZJ, Reynolds GP. Methylation at a transcription factor-binding site on the 5-HT1A receptor gene correlates with negative symptom treatment response in first episode schizophrenia. Int J Neuropsychopharmacol. (2014) 17:645-9. doi: 10.1017/S1461145713001442

100. Laursen L, Severinsen K, Kristensen KB, Periole X, Overby M, Muller HK, et al. Cholesterol binding to a conserved site modulates the conformation, pharmacology, and transport kinetics of the human serotonin transporter. $J$ Biol Chem. (2018) 293:3510-23. doi: 10.1074/jbc.M117.809046 
101. Oakes V, Domene C. Influence of cholesterol and its stereoisomers on members of the serotonin receptor family. J Mol Biol. (2019) 431:163349. doi: 10.1016/j.jmb.2019.02.030

102. Wei X, Nishi T, Kondou S, Kimura H, Mody I. Preferential enhancement of GluN2B-containing native NMDA receptors by the endogenous modulator 24S-hydroxycholesterol in hippocampal neurons. Neuropharmacology. (2019) 148:11-20. doi: 10.1016/j.neuropharm.2018.12.028

103. Avram M, Brandl F, Cabello J, Leucht C, Scherr M, Mustafa M, et al. Reduced striatal dopamine synthesis capacity in patients with schizophrenia during remission of positive symptoms. Brain. (2019) 142:1813-26. doi: 10.1093/brain/awz093

104. Kesby JP, Eyles DW, McGrath JJ, Scott JG. Dopamine, psychosis and schizophrenia: the widening gap between basic and clinical neuroscience. Transl Psychiatry. (2018) 8:30. doi: 10.1038/s41398-017-0 071-9

105. Marwarha G, Rhen T, Schommer T, Ghribi O. The oxysterol 27hydroxycholesterol regulates alpha-synuclein and tyrosine hydroxylase expression levels in human neuroblastoma cells through modulation of liver X receptors and estrogen receptors-relevance to Parkinson's disease. J Neurochem. (2011) 119:1119-36. doi: 10.1111/j.1471-4159.2011.0 7497.x

106. Rantham Prabhakara JP, Feist G, Thomasson S, Thompson A, Schommer E, Ghribi O. Differential effects of 24-hydroxycholesterol and 27hydroxycholesterol on tyrosine hydroxylase and alpha-synuclein in human neuroblastoma SH-SY5Y cells. J Neurochem. (2008) 107:1722-9. doi: 10.1111/j.1471-4159.2008.05736.x
107. Starkey NJE, Li Y, Drenkhahn-Weinaug SK, Liu J, Lubahn DB. 27Hydroxycholesterol is an estrogen receptor beta-selective negative allosteric modifier of 17beta-estradiol binding. Endocrinology. (2018) 159:197281. doi: 10.1210/en.2018-00081

108. Beasley CL, Honer WG, Bergmann K, Falkai P, Lutjohann D, Bayer TA. Reductions in cholesterol and synaptic markers in association cortex in mood disorders. Bipolar Disord. (2005) 7:449-55. doi: 10.1111/j.1399-5618.2005.00239.x

Conflict of Interest: The authors declare that the research was conducted in the absence of any commercial or financial relationships that could be construed as a potential conflict of interest.

Publisher's Note: All claims expressed in this article are solely those of the authors and do not necessarily represent those of their affiliated organizations, or those of the publisher, the editors and the reviewers. Any product that may be evaluated in this article, or claim that may be made by its manufacturer, is not guaranteed or endorsed by the publisher.

Copyright (๑) 2021 Sun, Zhao, Bo, Mao, He, Jiang, Li, Wang and Li. This is an open-access article distributed under the terms of the Creative Commons Attribution License (CC BY). The use, distribution or reproduction in other forums is permitted, provided the original author(s) and the copyright owner(s) are credited and that the original publication in this journal is cited, in accordance with accepted academic practice. No use, distribution or reproduction is permitted which does not comply with these terms. 